\title{
FEMINISMO E RESISTÊNCIA: \\ 1975 - O CENTRO DA MULHER BRASILEIRA E A REVISTA VEJA
}

FEMINISM AND RESISTANCE:

1975 - THE CENTRE OF WOMEN BRAZILIAN AND VEJA MAGAZINE

\author{
Ana Maria Marques* \\ anamariamarques.ufmt@gmail.com \\ Andreia Marcia Zattoni** \\ andreia.ufmt@gmail.com
}

RESUMO: O presente artigo pretende expor os debates presentes inicialmente no Centro da Mulher Brasileira (CMB), fundado em 1975, para mostrar as tendências do feminismo ali retratadas e analisar como o feminismo esteve presente na revista de informação semanal Veja, durante o ano de 1975, fazendo um contraponto com as discussões presentes no $\mathrm{CMB}$ na época. Entendemos que as tendências expostas no CMB foram influenciadas pelo momento histórico brasileiro e mundial, seja pelos debates feministas que aconteciam no exterior e que foram introduzidos no movimento, principalmente por mulheres que retornaram do exílio, ou pela militância de sócias que participavam da resistência à ditadura militar. A revista Veja expõe valores predominantes de uma época, todavia apresenta referências tímidas e por vezes preconceituosas sobre o feminismo.

Palavras-chave: Feminismo; Centro da Mulher Brasileira; Revista Veja.

* Doutora em História pela Universidade Federal de Santa Catarina. Professora do Departamento de História e do Programa de Pós graduação em História da Universidade Federal de Mato Grosso.

** Mestre em Filosofia pela Universidade Federal do Paraná. Procuradora educacional institucional na UFMT 
ABSTRACT: This article intends to expose the debates initially present in the Brazilian Women's Center (CMB), founded in 1975, to show trends portrayed there and examine how feminism attended the weekly information magazine Veja, during the year 1975, a counterpoint to the present discussions on CMB at the time. We believe that the trends exhibited in the $\mathrm{CMB}$ were influenced by Brazilian and world historical moment, is the feminist debates that took place abroad and which were introduced in the movement mainly by women who returned from exile, or the militancy of members who participated in the resistance military dictator ship. The Veja magazine exposes predominant values of a time, however, presents shy and sometimes prejudiced on feminism references.

KEYWORDS: feminism; Brazilian Women's Center; Veja magazine.

INTRODUÇÃO

Este artigo irá debruçar-se sobre o ano de 1975. O contexto é o Brasil, em plena ditadura militar. Ano paradigmático para o movimento feminista no Brasil, em setembro era fundado o Centro da Mulher Brasileira $(\mathrm{CMB})$, marco inaugural de um novo feminismo em nosso país. Também em 1975 foi declarado, pela Assembleia Geral da Organização das Nações Unidas (ONU), o Ano Internacional das Mulheres, quando aconteceu a Primeira Conferência Mundial sobre as Mulheres, na Cidade do México. Ainda no mesmo ano, a ONU oficializou por decreto o dia 8 de março como o Dia Internacional da Mulher. Em seguida, devido ao número de desafios apontados na busca da diminuição das desigualdades e discriminações, também foram declarados os anos de 1976 a 1985 como a Década da Mulher. Pretendemos expor as características do feminismo desse período, através dos princípios e debates presentes no $\mathrm{CMB}$, e analisar a presença de temas feministas na revista Veja durante o ano de 1975, fazendo um contraponto com as discussões presentes no CMB na época. 


\section{APRESENTANDO A REVISTA VEJA}

A Veja é uma revista de informação, da Editora Abril, que circula semanalmente desde 1968 até os dias atuais. Em 1975, seu diretor de Redação era Mino Carta, atualmente diretor de outra revista de informação, a Carta Capital. Na primeira edição de 1975, após apresentar o tema de capa, sobre a economia brasileira, Mino Carta lembrou os momentos políticos pelos quais passava o Brasil. Tempos de imposição de um regime autoritário, com perseguições políticas, episódios de tortura e censura aos meios de comunicação:

[...] 1975 é um ano chave para o definitivo e tão esperado encaminhamento de uma fórmula política destinada a restabelecer gradualmente no Brasil plenas liberdades democráticas, segundo os propósitos do governo do general Ernesto Geisel. Para uma operação tão complexa e vital, recomenda-se imaginação, certamente; a fantasia dos videntes, jamais. E pede-se tranquilidade nas águas da economia e a confiança dos que nelas navegam, em grandes ou pequenos barcos. (Veja, n. 330, jan. 1975, p. 17)

Uma referência tímida à necessidade de participação democrática contra a opressão vigente, compreensível diante das perseguições à imprensa e da censura aos veículos de comunicação. Lembremos que em 25 de outubro de 1975 morria o jornalista Vladimir Herzog, torturado até a morte nas dependências do DOI-Codi, em São Paulo, onde foi prestar depoimento por acusação de envolvimento em "atividades criminosas". O fato de Herzog ser membro do Partido Comunista, por si só, já era atestado de criminalidade para os militares no poder, que reprimiam manifestações a favor da restauração da democracia. Somente em março de 2013, graças aos trabalhos da Comissão Nacional da Verdade (CNV), a família de Herzog recebeu um atestado de óbito retificado (a ordem judicial para a retificação havia sido dada em 24 de setembro de 2012). Foi alterada a versão anterior 
de suicídio, para constar que sua morte "decorreu de lesões e maus-tratos sofridos em dependência do II Exército - SP (DOI-Codi)" ${ }^{\prime 1}$.

Diante desse contexto de censura, balizamos as informações que serão analisadas, compreendendo que um jornalismo mais autoral e crítico era difícil de ser praticado. Assim, sabemos que existiam omissões aos fatos de repressão conhecidos e que opiniões contrárias ao regime e a seus princípios eram vedadas. Porém, acreditamos que veículos de informação, e mesmo documentos oficiais, em qualquer tempo, mais ou menos democrático, sempre se constituem em uma possibilidade de leitura dos fatos históricos e que os discursos neles presentes revelam uma consciência de um grupo social ou de valores predominantes de uma época. É nesse sentido que os fatos sociais transformam-se em coisas, se solidificam, tornam-se duráveis e estáveis, condicionados por uma memória nacional, calcada em símbolos e manifestações. A memória nacional coletiva pode ter um caráter opressor e uniformizador, e ao não oportunizar outras falas e outros olhares sobre os acontecimentos, pode se configurar como uma estratégia de imposição de uma visão única sobre os fatos (POLLAK, 1989). Os veículos de comunicação atuam, por imposição ou por livre adesão, como construtores e divulgadores de signos e símbolos de uma dada perspectiva histórica. Assim aconteceu, por exemplo, no escamoteamento dos crimes de Stálin na antiga União Soviética ou na exaltação do nazismo na Alemanha, como também na construção do imaginário do golpe militar de 1964 como "revolução" que restauraria a ordem e alavancaria o progresso. Todavia:

Com os militares instalados no poder, começava a temporada de punições e violência praticadas pelo Estado. A montagem de uma estrutura de vigilância e repressão, para recolher informações e afastar do território nacional os considerados "subversivos" dentro da ótica do regime, e a decretação de Atos Institucionais arbitrários estiveram presentes desde os primeiros meses de governo. Num primeiro momento, esse sistema abateu-se principalmente sobre líderes sindicais e comunistas vinculados à luta pelas "reformas de base". O 
Ato Institucional decretado no dia 9 de abril de 1964 (posteriormente conhecido como Al-1) iniciava a temporada de cassações de mandatos de parlamentares e a suspensão dos direitos políticos dos "inimigos da revolução" (ARAUJO; SILVA; SANTOS, 2013, p. 17).

Ao analisar os textos presentes nas edições da revista Veja de 1975, temos clareza da impossibilidade de neutralidade diante dos fatos históricos do período, não somente porque havia censura às reportagens ali presentes, mas porque conceber a neutralidade diante da história seria ignorar a sua dimensão subjetiva, caindo em uma concepção pautada no cientificismo positivista.

CMB E O CONTEXTO HISTÓRICO DE SEU NASCIMENTO

Passados onze anos do golpe de 1964, após a clandestinidade e a extinção de muitos movimentos e organizações que lutavam, na sua maioria, não somente contra a ditadura instaurada no Brasil, mas contra o sistema capitalista que sustentava uma ordem econômica e social, sobreviviam ainda aqueles que continuavam resistindo à ditadura presente. As organizações de esquerda que surgiram no país foram motivadas por experiências bem-sucedidas na tomada de poder - a revolução socialista soviética e, principalmente, a chinesa e a cubana. Havia amplo debate, interna e externamente, entre as organizações na tentativa de consolidação de seus princípios, suas táticas e estratégias de luta. Três tendências ideológicas predominavam então, não somente no Brasil, mas em nível internacional - a revolucionária, a reformista e a conservadora -, como nos lembra Ciambarella (2007, p. 109):

Não só a sociedade brasileira, mas o mundo polarizou-se, no final dos anos 1960, em torno das posições reformistas, revolucionárias e conservadoras. Nesse sentido, a ação das esquerdas no Brasil foi além da oposição ao regime militar, convertendo-se em um movimento contestatório e revolucionário de maior amplitude, de rebeldia contra 
as instituições vigentes antes e depois do golpe, condicionado pelo contexto internacional, que atingiu seu apogeu com as manifestações de 1968.

As esquerdas brasileiras naquele período, pré e pós-64, já marcavam posições distintas. Algumas eram consideradas reformistas, como o Partido Comunista Brasileiro (PCB), acusado de imobilismo diante do golpe de 1964 e de defender, sem maiores críticas, o socialismo soviético, mesmo depois da denúncia dos crimes de Stálin no pronunciamento de Nikita Kruschev no XX Congresso do Partido Comunista da União Soviética, em 1956. Outros grupos, os revolucionários, por sua vez, também tinham suas divergências, alinhavam-se à ideologia trotskista, ou à marxista-leninista, ou à maoísta. Alguns defendiam a guerrilha com luta armada, outros, uma resistência a partir da proletarização, com a inserção de seus membros, a maioria estudantes de classe média, em fábricas, sindicatos e no ambiente rural, aos moldes da "guerra popular prolongada" da revolução chinesa. Essa última tendência, principalmente, terá reflexos no $\mathrm{CMB}$, como veremos adiante.

A influência da Igreja Católica, em especial com a formação das Comunidades Eclesiais de Base (CEBs) e dos grupos de jovens que deram origem à Juventude Operária Católica (JOC), à Juventude Estudantil Católica (JEC) e à Juventude Universitária Católica (JUC), também esteve presente na formação de muitos dos grupos de esquerda desse período, como é o caso da Ação Popular (AP), que elegeu várias diretorias da União Nacional dos Estudantes (UNE). O chamado cristianismo de libertação, muito presente no Brasil, tem suas origens históricas na eleição do papa João XXIII, em 1958, que realizou mudanças substanciais na cultura católica, como por exemplo a não obrigatoriedade de os ritos católicos serem proferidos em latim. Mas outras mudanças mais significativas, motivadoras de uma ação política concreta, ocorreram de forma gradual, como o enfoque em relação aos pobres: "Já não se trata de considerar o pobre como objeto de ajuda, proteção ou caridade, Hist. R., Goiânia, v. 19, n. 2, 2014 
mas como sujeito histórico, como ator de sua própria libertação" (LÖWY, 2007, p. 306). No entanto, a posição da ala conservadora da Igreja Católica, a sua maioria e de melhores posições hierárquicas, foi de aprovação ao regime de exceção dos militares. Em 1964, a Conferência Nacional dos Bispos do Brasil (CNBB), como ressalta Michael Löwy (2007, p. 305), assim pronunciase:

Atendendo à geral e angustiosa expectativa do povo brasileiro, que via a marcha acelerada do comunismo para a conquista do poder [...] Ao rendermos graças a Deus, que atendeu às orações de milhões de brasileiros e nos livrou do perigo comunista, agradecemos aos militares que, com grave risco de suas vidas, se levantaram em nome dos supremos interesses da nação, e gratos somos a quantos concorreram para libertarem-na do abismo iminente.

Mesmo com características libertárias, a ala mais progressista da Igreja Católica, fiel a sua doutrina, permaneceu conservadora em temas caros ao movimento feminista, como o aborto e o divórcio. $\mathrm{O}$ tema do aborto, principalmente, esteve presente nos debates entre as feministas do CBM, gerando conflitos e falta de consenso sobre a questão.

O Centro da Mulher Brasileira foi fundado em 8 de setembro de 1975, em pleno regime de exceção militar. Foi mais um movimento que nasceu no ambiente de autoritarismo, mas que tinha um objetivo definido: refletir sobre a condição da mulher na sociedade. Assim, as teorias marxistas ou maoístas presentes que permeavam as discussões eram mescladas, não sem polêmicas, a questões de cunho feminista. As ideias da Igreja Católica, mesmo que indiretamente, também estiveram presentes, com suas doutrinas, e mais uma vez essa presença gerou debates e conflitos. O presidente militar da época, o general Ernesto Geisel, anunciava uma abertura política lenta, gradual e segura. Nas eleições de 1974, o Movimento Democrático Brasileiro (MDB) conquistou para o Senado "16 das 22 vagas em disputa. Na Câmara dos Deputados, o partido teve $38 \%$ dos votos, contra $41 \%$ dados à Arena [Aliança Renovadora Nacional]" (MOTA, 2007, p. 301). O MDB também 
garantiu grande parte das prefeituras, principalmente nas grandes cidades. Em 1978, Geisel derrubou o Al-5, de 1968, ato institucional que delegava ao presidente da República, em caráter excepcional, o poder de cassar mandatos parlamentares; suspender os direitos políticos de qualquer cidadão, por até dez anos; decretar o confisco de bens considerados ilícitos; suspender a garantia do habeas corpus e decretar o recesso do Congresso Nacional. Porém, o processo de redemocratização, muito lento - e pouco seguro -, continuava contando com prisões políticas, mortes e desaparecimentos.

O CMB, em certa medida, foi um desdobramento dos grupos de reflexão que se formaram desde $1972^{2}$ :

Esses grupos eram constituídos apenas por mulheres - elas diziam que a presença de homens as inibia - que se reuniam nas casas umas das outras, ou em lugares públicos, como cafés, escritórios, bares e bibliotecas, para discutir problemas específicos das mulheres e se contrapor ao machismo vigente (PEDRO, 2012, p. 241).

Com a instituição do Ano Internacional das Mulheres, esses grupos sentiram-se fortalecidos para fundar uma organização de caráter institucional, mas não sem antes gerar intensos debates sobre essa decisão, pois uma parcela das mulheres envolvidas nos "grupos de reflexão" defendia que assim deviam permanecer, alegando maior liberdade de organização sem a centralidade de uma coordenação. Mas, vencendo a via institucional, o CMB foi criado. O momento político de 1975 exerceu forte influência em suas pautas de discussão. A luta pelo fim da ditadura parecia ser mais urgente e ditou o caminho inicial do grupo, expressando o momento histórico em que estava inserido.

O CMB foi um marco fundador do feminismo considerado de "Segunda Onda", que colocou as políticas do corpo no centro dos debates. As feministas envolvidas estavam imbuídas do propósito de "conscientizar as camadas populares" (PEDRO, 2012, p. 247). Aconteceram debates e diálogos com o setor jurídico: "[...] sobrelevava a preocupação com o Código Civil e 
o engajamento na luta pela libertação dos presos políticos com apoio ao Movimento Feminino pela Anistia - MFA" (SOIHET, 2007, p. 43). Prevaleceu, então, a tendência que focava nas estratégias e discussões contra a ditadura e a organização social capitalista e que defendia a luta de classes e a politização de mulheres de classes populares. Assim, a temática predominante no grupo foi aquela dedicada à mulher no mundo do trabalho: a luta por creches, por igualdade de remuneração em relação aos homens e proteção à maternidade. Muitas das mulheres que compunham o CMB participavam de outros movimentos de esquerda, organizações ou partidos e tinham um perfil mais ativista que os grupos de reflexão. Soihet e Esteves (2007, p. 367), comentando a participação de Moema Toscano ${ }^{3}$ no grupo, afirmam que ela:

Não descarta, inclusive, a influência partidária, já que algumas das mulheres se alinhavam com as propostas de seus partidos políticos. De acordo com a perspectiva marxista-leninista, boa parte das feministas se posicionava naquele momento como vanguarda revolucionária do movimento das mulheres, necessária para orientar as trabalhadoras em sua missão histórica. Legitimava-se, assim, articulando-se com os outros movimentos de luta pela redemocratização do país.

Esse alinhamento com as políticas partidárias muitas vezes se fazia necessário como estratégia de inserção na vida política pública, seja porque havia repressão imposta pelo regime ditatorial vigente ou porque o domínio masculino acontecia dentro dos partidos, também de esquerda. Embora as mulheres se proclamassem sujeitos políticos, muitos companheiros de movimento ainda discriminavam a sua presença, não thes delegando, por exemplo, o mesmo status de liderança que muitos homens conseguiam. Tega (2011, p. 2), citando Marcelo Ridenti (1993), nos dá um panorama da participação das mulheres nas organizações de esquerda:

Levando em conta tal contradição ao analisar os dados coletados no projeto Brasil: Nunca Mais, Marcelo Ridenti (1993) faz uma apresentação do perfil das organizações de esquerda dos anos 60 e 70 , as quais eram compostas por ampla maioria masculina. Do total de processados, apenas $16 \%$ eram mulheres. Desse número, $73 \%$ 
eram mulheres das camadas médias intelectualizadas, o que inclui estudantes, professoras e profissionais com formação superior. Considerando apenas as organizações armadas, verifica-se que $18 \%$ dos participantes processados eram mulheres e, dentre estas, 75\% eram das camadas médias intelectualizadas - número que contrasta com o pouco envolvimento de mulheres em partidos políticos tradicionais, como o PCB, onde menos de $5 \%$ do total de processados eram mulheres.

Além do mais, feminismo e temas como sexualidade, patriarcalismo, igualdade entre os sexos eram considerados dentro de alguns grupos como preocupações menores e de tendência burguesa. Esse ativismo, de modo particular, também era influenciado pela ideia de proletarização advinda das tendências maoístas. Essa concepção da proletarização dos membros revolucionários, presentes em algumas organizações das quais muitas mulheres do CMB faziam parte, incentivou a aproximação com as classes populares, como fica claro na fala de Moema Toscano: "Vamos levar as nossas verdades para as outras mulheres" (SOIHET; ESTEVES, 2007, p. 367). Predominavam nessa vertente as agendas de esquerda, priorizando a luta contra a ditadura e pelas liberdades democráticas, com espaço para temas relacionados à saúde, educação e trabalho da mulher. Nenhum de caráter especificamente feminista.

Outras mulheres do grupo, porém, tendiam a estar mais alinhadas ao feminismo mais amplo, atribuindo igual importância a diversas questões relacionadas ao universo feminino. Assim, ao lado de discussões sobre mercado de trabalho estavam questões a respeito da sexualidade. Esse ponto de atrito entre essas duas tendências sempre existiu no CMB. Os grupos de reflexão se contrapunham aos grupos de ação, as ativistas. Os primeiros discutiam temas referentes às demarcações rígidas dos papéis de gênero, às políticas do corpo, com discussões sobre sexualidade - aborto, prazer, contracepção. Outro assunto abordado era a distinção entre público e privado, fazendo o questionamento da restrição da mulher ao âmbito privado 
e ponderando o limite entre essas esferas, pois em ambas se consolidavam a dominação e se legitimavam as relações de poder. As teorias do sexo, negligenciadas pelas correntes marxistas, repudiavam tanto o determinismo biológico, como explicação para a condição de inferioridade da mulher, como o determinismo econômico como explicação acabada para a condição social, e nesse sentido vieram preencher um vácuo nas discussões presentes nos movimentos de esquerda.

Desde 1960 o livro O segundo sexo, de Simone de Beauvoir, já era lido, e Betty Friedan havia lançado sua obra $A$ mística feminina - ambos traduzidos e publicados em português em 1971. Questões e tendências discutidas fora do Brasil eram buscadas para inspirar os feminismos que começavam a ganhar destaque no país. O igualitarismo de gêneros, posição dualista ou binária, ou o "feminismo da diferença", passa a tomar força a partir dos anos 1970, procurando enfatizar os aspectos comuns entre mulheres e suas diferenças em relação aos homens. Contudo, ao final dessa mesma década e início dos 1980, parte das feministas da "Segunda Onda" começou a tomar outra direção, adotando a postura ginocêntrica ${ }^{4}$, que incorporaria outras identidades ao feminismo, como geração, etnias ou mesmo classe na perspectiva de gênero (NICHOLSON, 2000). Essas abordagens, embora posteriores ao período tratado, estavam despontando, embrionariamente, na fase final do $\mathrm{CMB}$ e nos movimentos que prosseguiram após a sua dissolução.

Com a anistia em 1979 e a volta de exiladas ao Brasil, temas propriamente feministas ganharam espaço nas discussões do CMB e nesse mesmo ano acontece o Encontro Nacional de Mulheres. Surgiram divergências sobre os temas dos seminários. A proposta do painel "Livre apropriação do corpo da mulher" gerou tensão entre as participantes. A vertente do $\mathrm{CMB}$ alinhada a questões da agenda partidária ainda prevalecia e se exteriorizou nesse momento, apontando diferenças entre a realidade brasileira e a estrangeira, de onde vinham muitas teorias que já enriqueciam 
o debate feminista. Após a proposta de um painel sobre o aborto, por um dos grupos, a discussão voltou à tona e, segundo Soihet e Esteves (2007, p. 371), realizaram-se três assembleias para definir a questão:

Intervenções sugerindo o adiamento do debate foram rebatidas. Uma das sócias reiterou sua posição contrária à introdução desse tema, recorrendo ao argumento de que as realidades da França e do Brasil eram muito diferentes, e além disso a posição da Igreja deveria ser considerada. Outras apoiaram tal posição, mencionando questões mais relevantes na sua perspectiva, como o trabalho das mulheres, necessidade de locais para deixar as crianças, salário, o que referendava a questão de que a discussão representaria o abandono de aliados, demonstrando seu alinhamento com as posições no CMB que subordinavam a problemática da mulher às questões gerais da sociedade.

O tema do aborto foi retirado da programação e ao final do Encontro deu-se uma ruptura no CMB que fez originar, em 1979, o Coletivo de Mulheres, que por sua vez deu origem à SOS Mulher, em 1981. O CMB permaneceu ativo por 25 anos, até 2000. Após a década de 1980, suas participantes foram abandonando a dupla militância, ou pelo menos distinguindo as especificidades e as novas incorporações de tendências e identidades ao movimento feminista.

FEMINISMO NAS PÁGINAS DA REVISTA VEJA

Durante todo o ano de 1975, os termos "feminismo" e "feministas" apareceram nas páginas da revista Veja em treze das 52 edições. Destas, sete não estavam associadas ao Brasil. As seis reportagens restantes referiam-se:

- a uma brincadeira da esposa do governador de Pernambuco no dia 1 o de abril, anunciando uma palestra da feminista Françoise Segan sobre o divórcio, que não aconteceu (Veja, n. 344 , abr. 1975 , p. 16$)$; 
- a um anúncio publicitário de Coleção de História, relacionando, ironicamente, o feminismo ao Código de Hamurabi (Veja, n. 348, maio 1975, p. 100);

- ao Clube de Cinema de Cidinha Campos em Campinas Homens não entram (Veja, n. 352, jun. 1975, p. 66);

- à conferência do Ano Internacional das Mulheres, no México, em duas matérias (Veja, n. 355, jun. 1975, p. 64-66 e n. 357, jul. 1975, p. 46-47);

- ao processo de cassação da prefeita de Rio Grande da Serra (SP), a qual não se autodeclarava feminista (Veja, n. 357, jun. 1975, p. 30);

- ao papel de uma atriz na novela Gabriela, que representava o feminismo no início do século XX (Veja, n. 370, out. 1975, p. 95).

Excetuando-se as duas reportagens sobre a Conferência no México, todas as outras são apenas citações de menor relevância.

Entre as matérias que abordam o feminismo fora do Brasil, temos duas entrevistas, nas páginas amarelas da revista. Uma delas com o escritor italiano Alberto Moravia, que trata da mulher em seus escritos e se autodeclara feminista, e outra com a sexóloga Helen Singer Kaplan, que se refere à participação do movimento feminista na chamada revolução sexual.

As reportagens restantes são:

- visita à Alemanha de Jihan Sadat, primeira-dama do Egito conhecida como uma das mais empenhadas combatentes em favor da emancipação feminina, onde ela declara que nos países árabes a tradição muçulmana leva a mulher a ocupar uma posição de segundo plano (Veja, n. 338, fev. 1975, p. 45); 
- votação da Câmara sobre o aborto, na Itália, dependente do parecer do Estado, que gerou protestos entre as feministas (Veja, n. 344, abr. 1975, p. 45);

- lançamento do livro da escritora norte-americana Erica Jong, que aborda a questão da sexualidade da mulher (Veja, n. 350 , maio 1975 , p. 104 );

- protesto da jornalista Françoise Giroud - na época trabalhando na L'Express -, que retirou seu nome do expediente da revista devido à adesão editorial à "onda erótica" na França (Veja, n. 366, set. 1975, p. 38);

- apresentação de documento sobre treze heresias modernas, por protestantes norte-americanos. O teólogo Harvey Cox, apoiado pela reverenda feminista Constance Parvey, apresentaram uma contralista de heresias, como, por exemplo: "Não deve haver igualdade para as mulheres dentro da Igreja" (Veja, n. 370, out. 1975, p. 56);

- vitória do primeiro-ministro conservador da Austrália, que ganhara as últimas eleições contra o partido trabalhista, que por sua vez era apoiado por grupos progressistas. Entre os apoiadores, a feminista Germaine Greer (Veja, n. 381, dez. 1975, p. 39).

Em relação ao aborto, tema de debates do $\mathrm{CMB}$, e que até nossos dias continua assunto controverso no Brasil, as principais referências na Veja é sobre o processo de sua legalização na Itália. Na reportagem que antecedia a Conferência da ONU sobre as mulheres, o repórter Renato de Moraes apontava que o assunto estava sendo barrado por ser considerado extravagante, e mais uma vez vemos a referência aos interesses das feministas italianas sobre o aborto, não sem antes chamá-las de radicais. 
Além disso, era montada uma espécie de cinto de castidade em torno da conferência para evitar temas considerados extravagantes ou perigosos. Enquanto isso, no resto do mundo, as ativistas mais radicais estavam exatamente preocupadas com esses assuntos. No início da semana passada, uma jovem italiana, logo depois de depositar seu voto nas eleições de segunda-feira, apresentou-se ao policial que montava guarda à urna dizendo: "Sou Emma Bonino, estou sendo procurada pela polícia. Considere-me presa". A senhorita Bonino, 27 anos, tinha ordem de prisão desde janeiro, quando admitiu ser a dinâmica presidente do Centro Italiano de Esterilização e Aborto (CISA), entidade considerada fora da lei (Veja, n. 355, jun. 1975, p. 64).

Na mesma reportagem, aparecem estereótipos e preconceitos em relação às feministas, deixando evidente a resistência às mulheres que levantavam bandeiras contra o predomínio machista nas relações sociais e de poder. Ao identificarem um desequilíbrio nas relações de gênero, eram também classificadas como não correspondentes à imagem idealizada de mulher: um ser delicado, dedicado, cuidadoso, submisso, discreto, polido etc. Temos, já no primeiro parágrafo, uma referência ao lesbianismo, com menção à personagem hebraica Lilith: "Se tivesse que deixar o mundo das trevas [...] para participar de alguma solenidade do 'ano da mulher', Lilith certamente compareceria à inauguração [...] de um campo de férias para senhoras e senhoritas homossexuais [...]" (Veja, n. 355, jun. 1975, p. 64). E a matéria prossegue com a ridicularização de assuntos sobre sexualidade, com insinuações de promiscuidade, exemplificando com um episódio "insuperável" de um encontro do escritor Norman Mailer e feministas norteamericanas: "Duas mulheres presentes fizeram questão de demonstrar a Mailer, numa rápida e acrobática exibição de sexo, que o instrumental masculino pode ser dispensável" (Veja, n. 355, jun. 1975, p. 65). Ainda, faz uso do adjetivo "magoadas", insinuando ressentimento nas feministas: "Magoar-se em silêncio é a característica básica da diluída sucursal brasileira do Women's Lib" (Veja, n. 355, jun. 1975, p. 66). Sempre com um tom irônico, citam-se manifestações contrárias à conferência: 
"Ano Internacional da Mulher? O que é isso? Será um super dia das mães?", indagava uma ativista americana ouvida em Nova York por Hugo Estenssoro, de VEJA. "Qual será o próximo ano? O ano internacional do queijo camembert?", pergunta um panfleto das Petroleuses, um dos grupos feministas mais ativos da França (Veja, n. 355, jun. 1975, p. 65).

O repórter aponta, também, o feminismo como foco de ironia e repressão por parte da sociedade, e sugere que no Brasil só havia supostas feministas que não sabiam o que era o feminismo e que, por isso, não gostavam sequer de ser chamadas de feministas. Nessa passagem vemos a imagem da feminista como pessoa masculinizada, em oposição ao estereótipo de graciosidade, delicadeza, meiguice que pairava no ideário sobre o feminino e que contribuía para a discriminação da mulher. O tema dos estereótipos femininos estava em voga na época entre as feministas, sendo abordado em alguns estudos no CMB.

Mesmo não sendo feministas, algumas dessas mulheres, cerca de dez, estarão no México para encontros e seminários paralelos à conferência. Quanto às feministas oficiais, representantes do governo, elas também fazem questão de dizer que não são feministas, até muito pelo contrário. Uma delas, Maria Alice Silva, alta funcionária do Ministério do Trabalho, admite inclusive que uma das maneiras mais práticas para uma mulher se realizar é um casamento feliz. Outra delegada brasileira, a veneranda fundadora da Federação Brasileira pelo Progresso Feminino (FBPF), Bertha Lutz, atualmente com 80 anos, recorda-se ainda dos tempos em que criou a FBPF no longínquo ano de 1916, quando as leis brasileiras consideravam os índios, os loucos, os menores e as mulheres parcialmente incapazes. Realmente, de 1916 para cá a situação da mulher brasileira mudou muito a ponto de muitas vezes graciosas jovens serem confundidas com rapazes, dado o seu comportamento determinado e autossuficiente (Veja, n. 355, jun. 1975, p. 66).

Dominique Fougeyrollas-Schewebel (2009) explica que o movimento feminista da década de 1970 seguia três tendências: socialista, liberal e radical. Os dois primeiros tendiam a se ligar aos partidos de esquerda, e o terceiro era o que se destacava pela militância das lésbicas, cuja luta se 
dava contra o sistema patriarcal e as formas diretas e indiretas do poder falocrático.

O fato de muitas mulheres recearem se declarar feministas devia-se, em parte, à associação direta com o lesbianismo ou as reivindicações consideradas anticristãs. A denominação institucional do Centro da Mulher Brasileira, sem incorporar a palavra "feminismo", não é fortuita. A questão foi levantada quando da sua fundação e decidiu-se pela não utilização do termo "feminista" por receio de repressões.

Além de todas essas críticas, formuladas pelas próprias colegas de feminismo, as mulheres envolvidas em grupos de reflexão enfrentavam o forte preconceito então existente na sociedade brasileira contra o feminismo. Esse preconceito também atingia as militantes que atuavam nos Centros da Mulher, na elaboração de periódicos e nas reuniões com mulheres de bairros populares. Não foram poucas as vezes que as feministas se viram constrangidas a afirmar que não eram "contra os homens". Muitas ativistas também achavam importante deixar claro que não eram lésbicas (epíteto frequentemente atribuído às feministas na época). Além disso, embora no interior dos periódicos que publicavam com suas ideias a identificação com o feminismo estivesse expressa em palavras, os títulos referiam-se à mulher ou às mulheres, e não ao feminismo. A ausência de referências explícitas ao feminismo é significativa. De fato, o antifeminismo era muito forte na sociedade brasileira dos anos 1970 e 1980. (PEDRO, 2012, p. 249)

Na reportagem que faz um balanço da conferência sobre o Ano Internacional das Mulheres, o repórter Sebastião Gomes Pinto mantém o mesmo tom irônico. Já na abertura, citando o presidente do conclave, declara: "[...] as mulheres não estão dizendo nada de novo. Tudo já foi dito". E destacando a falta de organização, de definição de temas comuns e de excesso de opiniões e de interesses diversos, insinuando incapacidade nas mulheres presentes, continua:

Uma perceptível insegurança dominou a maioria dos oradores, já que uma regra quase geral aplicada nos debates foi o da mútua desconfiança. [...] Sempre vigilante, a senhora Friedan chega a afirmar que um dos tumultos foi provocado por um grupo que invadiu o Medical 
Center comandado por dois homens. Segundo ela, esse grupo seria integrado tanto por direitistas como por esquerdistas e acrescentou ter vislumbrado no grupo mulheres cubanas e notórias representantes de setores ultraconservadores da Argentina. Trata-se sem dúvida de uma insólita salada de ideologias, posições políticas e sexos, mas que de certa maneira sintetiza o que foi a conferência. Ainda faltavam cinco dias para o encerramento. [...] Sobre esse fantástico painel de teses, opiniões e preocupações específicas de determinados grupos, teria de pairar fatalmente o caos. (Veja, n. 357, jul. 1975, p. 46)

Na matériaé salientadaa sobreposição de temassocioeconômicos aos "de exclusiva pertinência ao sexo feminino", como o de dispor livremente de seu corpo. Ao atribuir importância ao evento, destaca questões sobre a luta por justiça social em relação à igualdade econômica, tema amplamente presente nas agendas de esquerda e que predominou por muito tempo na agenda do CMB. Assim Gomes Pinto encerra a reportagem: "De qualquer forma foram lançadas no México algumas sementes que poderão florescer no futuro. A mais óbvia é a de que as mulheres - e implicitamente também os homens - devem lutar com vigor por uma ordem econômica mais justa sobre a face da Terra" (Veja, n. 357, jul. 1975, p. 47). Ao desqualificar o evento, destacando uma suposta desorganização, a revista acaba por esvaziar o conteúdo dos debates divergentes.

\section{PALAVRAS FINAIS}

A análise do movimento feminista da década de 1970 no Brasil leva-nos a perceber que questões relativas à defesa dos direitos da mulher (direitos trabalhistas que incluíssem a garantia de creche, de licençamaternidade e aposentadoria, por exemplo) eram revisitadas com mais empenho que em décadas anteriores. A luta contra o preconceito sexista permanecia também na pauta das feministas, com ênfase então no direito de decidir sobre o seu próprio corpo - decidir sobre a maternidade parecia 
algo revolucionário, considerando que durante séculos houve um grande investimento discursivo que criou uma cultura da maternidade como parte (compulsória) da "natureza feminina". Laqueur lembra que, no século XVIII, o sexo que nós conhecemos foi inventado:

Quando o próprio corpo natural tornou-se o padrão de ouro do discurso social, o corpo da mulher tornou-se o campo de batalha para redefinir a relação social antiga, íntima e fundamental entre o homem e a mulher. $\mathrm{O}$ corpo reprodutivo da mulher na sua concretude corpórea cientificamente acessível, na própria natureza dos seus ossos, nervos e principalmente órgãos reprodutivos, passou a ter um novo significado de grande importância. Os dois sexos, em outras palavras, foram inventados como um novo fundamento para o gênero. (LAQUEUR, 2001, p. 190)

Embora muitas bandeiras pudessem não parecer novas, como a própria revista Veja aponta, os contextos eram diversos. O elemento particular que uniu muitas mulheres foi a perda de maridos, filhos(as) e netos(as) nos cadafalsos da ditadura, no Brasil, no Chile, na Argentina... Também existiram aquelas, não menos importantes que os homens, que pegaram em armas nos movimentos de guerrilha ou que participaram ativamente das guerrilhas, mesmo impedidas de exercer funções de liderança, sem precisar ir para a luta armada. Segundo Ana Alice Costa, que conheceu a militância feminista dos anos 1970 no México e continuou no Brasil ao voltar em 1981:

Essa nova onda feminista chegou ao Brasil em um momento muito peculiar da nossa história, em pleno regime militar instalado a partir do Golpe militar de 1964. Muitas das suas integrantes eram oriundas de organizações da chamada "Esquerda Revolucionária" vinculadas a uma perspectiva marxista de liberação nacional. Essas e outras vivenciaram a experiência da luta armada, da clandestinidade, das prisões, da tortura, do exílio e, em especial, vivenciaram o autoritarismo e o sexismo tanto das organizações da esquerda na qual militavam quanto da direita através dos mecanismos repressivos do Estado. (COSTA, 2010, p. 176)

Devido ao contexto histórico, não somente brasileiro, mas mundial, com diversos focos de governos ditatoriais, como a Espanha e 
Portugal, por exemplo, agendas de combate à repressão e de luta para a redemocratização eram urgentes e acabaram se sobrepondo aos assuntos de gênero, embora fossem pungentes. Essas posturas distintas nos grupos de ação e nos grupos de reflexão da CMB não eram tão bem definidas na época, mesclando-se muitas das questões priorizadas por ambos. A fértil heterogeneidade do feminismo no Brasil acabou contribuindo para um amplo debate, ora tímido, ora acalorado.

Quanto à imprensa, sabemos do poder da mídia na construção e na manutenção de valores e de poderes estabelecidos, por isso podemos inferir que a revista Veja foi também um braço ideológico, pois formador de opinião, da ditadura que, por sua vez, não foi só militar, pois setores civis ligados à mídia, a exemplo aqui da Veja, não só apoiaram a repressão como a integraram, constituindo um de seus pilares. Bernardo Kucinski, jornalista e professor da Universidade de São Paulo (USP), que participou ativamente da imprensa alternativa, era jornalista da Veja na década de 1970 e relata que o periódico teve a oportunidade de denunciar as torturas acontecidas no período. A revista preparou um dossiê que foi entregue ao presidente Médici. Essa atitude custou o exílio dele e de Ítalo Tronca para a Inglaterra. No exterior, publicaram o dossiê que falava das torturas e da violência militar. Kucinski fala sobre esse momento:

[...] foi o momento do fracasso da imprensa brasileira. Eu tive uma sensação aguda que se naquele momento o resto da imprensa seguisse a direção que a Veja estava dando, talvez [nós da imprensa] teríamos interrompido esse processo terrível que houve depois de desaparecimento, de mortes... Mas a nossa imprensa não seguiu 5 .

Em nossa análise verificamos que o feminismo não foi ignorado pela Veja, mas já se esboçou a grande barreira que os movimentos feministas enfrentavam, visível no preconceito expresso, sobretudo, nas reportagens analisadas sobre a convenção do Ano Internacional das Mulheres. O retrato do feminismo na revista Veja expõe o que se queria esconder. Percebe-se a 
resistência em reconhecer e atribuir seriedade aos temas feministas, postura de uma mídia conservadora, quando não omissa - e até perversa - no que diz respeito aos movimentos sociais.

NotAS:

1 Sobre a recomendação da Comissão Nacional da Verdade, ver: <http://www.cnv.gov.br/ index.php/institucional-acesso-informacao/realizacoes-da-cnv>. Acesso em: 15 abr. 2014.

2 "Branca Moreira Leite, que estudara em Berkeley, nos Estados Unidos, e lá participara por três meses de um grupo de reflexão, trouxe para o Rio de Janeiro sua prática de organização. O grupo carioca adotou o nome de Grupo de Reflexão e durou até 1973” (PEDRO, 2012, p. 242).

3 Moema Toscano é licenciada em Educação Física e em Ciências Sociais, bacharel em Direito e livre-docente em Sociologia pela PUC-RJ. Professora aposentada, dedica-se atualmente à publicação de trabalhos no campo da educação e do feminismo.

4 Grosso modo, ginocêntricas são mulheres que se identificam com mulheres, ou seja, trata-se do feminismo lésbico.

5 A entrevista completa, transmitida pela TV Brasil no dia 17 de março de 2014, foi transcrita e publicada na coluna de Luís Nassif, no jornal GGN. Disponível em: $<$ http://jornalggn. com.br/noticia/kucinski-das-lutas-jornalisticas-as-denuncias-sobre-tortura $>$. Acesso: 15 mar. 2014.

\section{REFERÊNCIAS}

ARAUJO, Maria Paula; SILVA, Izabel Pimentel da; SANTOS, Desirree dos Reis. Ditadura militar e democracia no Brasil: história, imagem e testemunho. Rio de Janeiro: Ponteio, 2013.

CIAMBARELLA, Alessandra. Do cristianismo ao maoísmo: a história da Ação Popular. In: FERREIRA, Jorge; REIS, Daniel Aarão (org.). Revolução e democracia (1964...). Rio de Janeiro: Civilização Brasileira, 2007.

COSTA, Ana Alice A. O feminismo brasileiro em tempos de ditadura militar. In: PEDRO, Joana Maria; WOLFF, Cristina Scheibe (org.) Gênero, feminismos e ditaduras no Cone Sul. Florianópolis: Mulheres, 2010. 
FOUGEYROLLAS-SCHWEBEL, Dominique. Movimento Feminista. In: HIRATA, Helena et al. (org.). Dicionário crítico do feminismo. São Paulo: Unesp, 2009.

LAQUEUR, Thomas. Inventando o sexo: corpo e gênero dos gregos a Freud. Rio de Janeiro: Relume Dumará, 2001.

LÖWY, Michael. As esquerdas na ditadura militar: o cristianismo da libertação. In: FERREIRA, Jorge; REIS, Daniel Aarão (org.). Revolução e democracia (1964...). Rio de Janeiro: Civilização Brasileira, 2007.

MOTA, Rodrigo Patto Sá. O MDB e as esquerdas. In: FERREIRA, Jorge; REIS, Daniel Aarão (org.). Revolução e democracia (1964...). Rio de Janeiro: Civilização Brasileira, 2007.

NICHOLSON, Linda. Interpretando o gênero. Estudos Feministas, Florianópolis, v. 8. n. 2, p. 9-41, 2000.

PEDRO, Joana Maria. O feminismo de "Segunda Onda" - corpo, prazer e trabalho. In: PEDRO, Joana Maria; PINSKY, Carla B. (org.). Nova História das Mulheres no Brasil. São Paulo: Contexto, 2012.

POLLAK, Michael. Memória, esquecimento, silêncio. Estudos Históricos, Rio de Janeiro, v. 2. n. 3, p. 3-15, 1989.

RIDENTI, Marcelo. O fantasma da revolução brasileira. São Paulo: Unesp, 1993.

SOIHET, Rachel; ESTEVES, Flávia Cópio. O Centro da Mulher Brasileira (CMBRJ) e suas experiências nos anos 1970 e 1980. In: FERREIRA, Jorge; REIS, Daniel Aarão (org.). Revolução e democracia (1964...). Rio de Janeiro: Civilização Brasileira, 2007.

SOIHET, Rachel. Preconceitos nas charges de $O$ Pasquim: mulheres e a luta pelo controle do corpo. ArtCultura, Uberlândia, v. 9, n. 14, p. 39-53, jan.-jun. 2007.

TEGA, Danielle. Reflexões sobre o feminismo brasileiro: paradoxos e elaboração da experiência. Anais II Simpósio Gênero e Políticas Públicas. ISSN2177-8248. Universidade Estadual de Londrina, 18 e 19 de agosto de 2011. Disponível em: <http://www.uel.br/eventos/gpp/pages/arquivos/ Danielle.pdf>. Acesso em: 10 nov. 2013. 